\title{
Goal Setting for Persuasive Information Systems: Five Reference Checklists
}

\author{
Sainabou Cham, Abdullah Algashami, John McAlaney, Angelos Stefanidis, Keith \\ Phalp, Raian Ali \\ Bournemouth University, UK \\ \{scham, aalghashami, jmcalaney, astefanidis, kphalp, \\ rali\}@bournemouth.ac.uk
}

\begin{abstract}
The concept of goals is prominent in information systems and also artificial intelligence literature such as goal-oriented requirements engineering and self-adaptive systems. Digital motivation systems, e.g. gamification and persuasive technology, utilise the concept of behavioural goals which require a different mind-set on how to elicit and set them up, how to monitor deviation from such goals and how to ensure their completion. Behavioural goals are characterised by a range of factors which are not the main focus in classic information systems and AI literature such as self-efficacy, perceived usefulness. To engineer software supporting goal setting, a concretised taxonomy of goals would help a better-managed analysis and design process. In this paper, we provide a detailed classification of behavioural goals and their associated properties and elements (types, sources, monitoring, feedback, deviation and countermeasures). As a method, we review the literature on goal setting theory and its application in different disciplines. We subsequently develop five reference checklists which would act as a reference point for researchers and practitioners in persuasive and motivational systems.
\end{abstract}

Keywords: Goal Setting, Persuasive Systems, Behavioural Goals.

\section{Introduction}

Goal Setting Theory relates to the relationship between people and goals. It includes how people set up goals, how they react to them, and how they use them to attain behavioural change [1]. Goal setting research is informed by cognitive psychological theories, which demonstrate how a person's perception of their skills, and the usefulness and ease of achieving a specific goal, play a vital role in being successful in meeting that goal [2]. Goal setting is a core element of various persuasive information system paradigms, such as gamification [3] and persuasive technology [4, 5]. A persuasive system is an information system intended to strengthen, change or shape states of mind or behaviour or both without utilising pressure, this might delay or avoid the onset of a range of medical problems, and enhance the quality of life [6, 7].

Goal setting is a core element of various techniques and principles within persuasive technology. In terms of Fogg's mechanisms [8], goal setting relates to reduction 
and tunnelling where smaller steps lead to a bigger goal; self-monitoring, where goal achievement is tracked and enforced; surveillance where peers monitoring can put pressure towards goal achievement and, conditioning, where failure or success in meeting goals is rewarded accordingly. Regarding Cialdini's principle of influence [9], goal setting correlates well with the commitment and consistency principle, where people remain motivated to sustain a behaviour that helps or has helped them to achieve a behaviour change goal. In particular, self-set or agreed goals require a commitment that then boosts the degree of adherence to the goal [10].

Research on goal setting can be found across a wide range of disciplines. This includes the domain of management and business administration where the emphasis is on productivity and supporting business achievement of tactic and strategic goals [11], and the domain of social psychology, e.g. the use of goal setting within groups in which social relationships become an integral part of goal definition and achievement [12]. Similarly, targeted behaviour in theories of reasoned action [13] and planned behaviour [14] can be defined as a goal. These theories highlight that the selfperception of the ability to meet a goal affects the commitment and adherence to plans to reach it.

In this paper, we present five reference checklists developed based on reviewing the literature on goal setting theory and its application in various domains. Producing reference checklists for goal setting that concretise the concept and depict its common and variable components will help to achieve better software and automation of behavioural goals support.

At the start of the research, we made a proposition that behavioural change goals introduce the need for a new mindset when dealt with as requirements in persuasive systems. Informed by goal-setting theory [1] and the literature on goal-oriented requirements engineering [15], we defined five main pillars of behavioural goals to guide our investigation. These pillars are sources of behavioural goals, goal identifiers, goal elicitation, monitor and feedback, deviation and countermeasures. After setting the initial template, we reviewed the relevant literature to inform our approach to constructing the five goal setting reference checklists. We reviewed the research on goal setting in various communities, including behavioural economics, persuasive technology, and health and environmental sciences. We only considered papers which adopted goal-setting as their primary research strategy and provided a description of how it was used. Search criteria used to obtain the relevant work included variations and combinations of keywords, incorporating terms such as goal setting, behavioural goals, persuasive systems, and behavioural change. We used snowballing approach [16], starting with influential papers in the field which led to further references.

\section{Behavioural Goals: Five Reference Checklists}

\subsection{Sources of Behavioural Goals}

The source of goals represents the party who sets the goal. Based on the literature review findings, we identified five sources of goals; Table 1 provides a brief description of each source of behavioural goals. By experts, we mean a behavioural change expert. By subjects, we mean the people who are to achieve goals. 
Table 1. Sources of Behavioural Goals

\begin{tabular}{|l|l|}
\hline $\begin{array}{l}\text { Source } \\
\text { Self-set }\end{array}$ & Description \\
\hline Assigned & The experts designed goals with no subjects input \\
\hline $\begin{array}{l}\text { Participatory } \\
\text { Guided }\end{array}$ & $\begin{array}{l}\text { Soabjects are gesigen directions by experts on how to choose a goal, but the choice is left } \\
\text { for them to make }\end{array}$ \\
\hline Group-set & Goals are designed and chosen within a group, typically facilitated by an expert
\end{tabular}

There are some factors to consider when deciding the suitability of each source of goal in the behavioural change process. These include:

Problem Origin plays a vital role in the decision about the subjects' level of involvement in the behavioural goal specification process. A subject's behaviour could be influenced by factors relating to social and individual context [17]. The social context refers to the social influence of and peer pressure on a subject's behaviour, and the individual factors refer to the beliefs, values and state of mind of the subject. Any intention to change the subject's behaviour should, therefore, take into account such influencing factors. If the social context is the origin of the problem, then the behavioural goals would need to be set collaboratively, agreed upon and committed to by the subjects, with help from an expert. If the problem originates from individual factors, such as the subject's personality, or the pleasure derived from performing the behaviour, consideration would be necessary for assessing variables such as personality, the stage of change and treatment levels before selecting a source for the goals.

Self-efficacy refers to one's belief that one has the skills and abilities required to attain the goals. Subjects with a higher self-efficacy, tend to be more committed to their goals, as they are likely to come up with better strategies and put in more effort towards goal attainment [18]. When goals are to be set collaboratively, the selection of subjects should be based on their skills and abilities to attain the goals. Subjects selfefficacy can be increased by employing specific persuasion techniques, such as providing information about the require approaches for goal-related tasks.

Behavioural change state affects the ability of subjects to set goals and their receptiveness to external goal sources. For users in the contemplation stage, self-set goals could be avoided as the users may be defensive about their behaviour and may be in denial or biased when expressing goals [19]. When this is the case, we might consider choosing participatory, guided, group-set or even assigned goals. Self-set goals would fit those in the advanced stages of change, i.e. users who have already started to implement the behavioural change.

\subsection{Behavioural Goal Identifiers}

Various properties describe goals. The goals can be influenced by specific moderating variables relating to the person or their group context. Table 2 provides a summary. 
Table 2. Behavioural Goals Identifiers

\begin{tabular}{|c|c|}
\hline Goal Properties & Description \\
\hline Proximity & $\begin{array}{l}\text { The time by which the goals is to be achieved; Distal (goals set on a long-term } \\
\text { basis) or Proximal (goals based on short-term goals) }\end{array}$ \\
\hline Goal specificity & The precision and granularity of what is to be achieved \\
\hline Goal difficulty & The effort required from a subject for goal attainment \\
\hline Goal Moderators & Description \\
\hline Commitment & $\begin{array}{l}\text { The importance of goal attainment and an individual's determination to } \\
\text { achieve the goal defined by subjects': } \\
\text { - Self-efficacy or believing in one's ability to achieve the goal } \\
\text { - Perception of usefulness, and the significance of achieving the goal }\end{array}$ \\
\hline Feedback & The knowledge of performance progress in relation to attaining goals \\
\hline Task complexity & $\begin{array}{l}\text { The complex nature of a task defines the level of effort, skills, and also the } \\
\text { strategy required to attend the goal }\end{array}$ \\
\hline
\end{tabular}

Proximity refers to how far into the future goals are set. Setting proximal goals, in addition to distal goals, could enhance performance [1] and self-efficacy [20], because they provide a relatively quick sense of achievement in the short-term, leading to sustained performance. For example, a distal goal to spend less time online this month could be attained by setting proximal goals such as to reduce the time spent online by 20 minutes a week. Also, goal proximity could help lessen the loss of goal interest, increase motivation and confidence toward goal attainment. In persuasive systems, users could be motivated to set proximal goals by awarding gamification elements such as points to a user when goals are self-set or collectively when the behavioural change goals are set in a group.

Commitment refers to the status of a person dedicated to a goal. In [1], two factors are found to influence commitment; (1) the importance of goal attainment, and (2) self-efficacy. Elsewhere in [21], external influences (peer influence, authority), interactive influences (participation and competitiveness), and internal factors (expectancy and internal rewards) are outlined as elements which could define commitment. To improve commitment, when goal setting is performed collaboratively, the individuals involved could make a collective commitment to attaining the goals. When the goal is assigned, the subject's commitment tends to reflect their self-efficacy levels; therefore, assessing self-efficacy before assigning goals could be essential in gauging the subject's commitment to the goals.

\subsection{Behavioural Goal Elicitation}

The main techniques to elicit behavioural change goals are listed in Table 3. We comment on the main types in the following. Interviewing as an elicitation method could be used at the initial stages of implementing the system. The technique can capture in-depth information relating to a subject's behaviour. During the interview process, subjects could be encouraged to reflect on their emotional state, the behaviour which needs to change and how they plan to change such behaviour. The findings from this activity could then be used to determine the correct behavioural change 
goals, but also assess the eligibility of subjects pursuing a behavioural change goal as employed in [22]. Diaries could enable the capturing of events as they happen. This information may be used to help identify adverse behavioural issues and possible techniques to act as countermeasures. In [23], diary entries were used to gather student motivation strategies, employed for improving their school work, demonstrating a self-regulatory process for managing learning.

When goals are set collaboratively, group discussion could be more useful as it enables a debate amongst the subjects to help understand their behaviour, and consequently, the setting of goals. Furthermore, obstacles to goal attainment and strategies for overcoming such obstacles could be addressed more efficiently in such a grouptherapy style [24]. The social element of a group discussion could lead to better goal performance, as a result of peer influence and the ability to make a collective commitment to the goals of a group [25]. Algorithms could be used to learn and understand the behaviour and behaviour pattern of subjects, by performing behaviour analysis on their historical activity data.

Table 3. Behavioural Goal Elicitation Methods

\begin{tabular}{|l|l|}
\hline $\begin{array}{l}\text { Elicitation Method } \\
\text { Interview }\end{array}$ & \multicolumn{1}{c|}{ Description } \\
\hline Diary Study & Used when in-depth understanding is required \\
\hline $\begin{array}{l}\text { Group discussion } \\
\text { Counselling }\end{array}$ & Used for discussing barriers and strategies for alleviating them \\
\hline Brainstorming & Used for helping subjects understand their behavioural change needs \\
\hline Observation & Used for discovering bespoke strategies for reaching the goal \\
\hline Algorithms & Used for assessing behaviours in a natural setting \\
\hline
\end{tabular}

\subsection{Behavioural Goals Monitoring and Feedback}

Our fourth checklist is related to the monitoring and feedback strategies used to assess and enhance behavioural goal attainment. Table 4 provides a summary.

Table 4. Behavioural Goals Monitoring \& Feedback

\begin{tabular}{|l|l|}
\hline $\begin{array}{l}\text { Monitor } \\
\text { Feedback Content }\end{array}$ & $\begin{array}{l}\text { Monitor and Feedback } \\
\text { Self-monitoring; Peer monitoring; Automated } \\
\text { feedback; Comparative feedback (Self-comparisons; Social comparisons) }\end{array}$ \\
$\begin{array}{l}\text { Feedback Timing } \\
\text { Feedback Framing }\end{array}$ & Reflection during the behaviour; Reflection after the behaviour \\
\hline
\end{tabular}

Monitor refers to the agent who collects behavioural metrics and progress status. Monitoring can be performed by the subjects, by peers or be computerised.

- Self-monitoring refers to the responsibility of a subject to observe and reflect on their behaviour and goals. Self-monitoring is performed by recording and tracking goal-related activity, and by evaluating the progress made. Reminders and jour- 
naling, in the form of a progress bar or timers, could help individuals perform selfmonitoring and increase their awareness of their behaviour [26].

- Peer-monitoring refers to other individuals observing a subject's behaviour, possibly on mutual understanding. Peer-to-peer monitoring could lead to social relationship breakdown if the feedback method implemented is not carefully designed, as it may be viewed as spying [27]. Peer monitoring could be useful in relation to behavioural change when goal setting is performed collaboratively. Hence, the surveillance is seen positively as part of behaviour awareness and change.

- Automated monitoring is based on the use of sensors and communication technology, e.g. geographic location and heart rate monitoring via a smartwatch. The accuracy and intensity of monitoring could empower individuals to gain insight into their behaviour or pattern of behaviour. However, the lack of privacy and anxiety could have negative consequences. Also, automated monitoring may fail to capture the intention and context of the behaviour. This may necessitate a blended approach putting together self-monitoring or peer monitoring with an automated one.

Feedback content refers to the central theme in the feedback informational content.

- Motivational feedback informs subjects how well they perform towards their goals and encourages them to continue in the same way or perform better. Performance could be rewarded by employing gamification elements such as points, badges and avatars. Competitive rewards and game mechanics, such as the leader-board, need to be avoided as they may distract from the primary goal or the spirit of the ultimate behavioural change goal, especially when goals are set collaboratively.

- Learning feedback helps subjects to learn the consequences of specific committed or avoided behaviours [22]. This feedback needs a clear rationale. For example, in regulating printing behaviour, when a subject prints ten articles daily while the goal is not to exceed four articles a day, the feedback should clarify how the deviation from goal occurs, and show the subject how this was manifested in their printing behaviour.

- Performance feedback shows a subject's performance toward their goal and could be used to help determine the chances of attaining behavioural goals. This feedback could help persuade the subjects who are committed, motivated, and have the right ability, to put in more effort and time when a discrepancy is detected between the feedback provided and their behavioural goal.

- Outcome feedback represents the knowledge of results; subjects should be able to have the skills required to evaluate whether the outcome feedback represents a good or poor performance toward the goal.

- Comparative feedback compares subjects to their past goal performance (selfcomparison) or to the performance of their peers when the collaborative goal setting is adopted (social comparison). Self-comparison may work better when selfmonitoring is employed and may fit well those subjects with lower self-esteem. Social-comparison works by comparing goal performance within a social circle to motivate individuals to attain their goals. It may also lead to competition and conflict between subjects within the same group or between groups if an inter-group comparison is adopted. This could negatively impact self-esteem and self-efficacy. 
Feedback timing is concerned with the right timing of feedback message so that it is seen as a motivational tool and its acceptance is increased. Feedback can be delivered while the behaviour is taking place (reflection during usage) for real-time awareness or afterwards (reflection after usage) for off-line learning and future planning.

Framing refers to the language used in the message content of the feedback in style and orientation. The feedback may not have the desired effect when the subjects view it as strict or consisting of threatening messages [28]. The language used relates to what extent the feedback is consistent with the subjects' attitudes and preferences, e.g. whether the message is a gain or a loss frame, strict, precise, or personal. Loss frame refers to feedback which shows a negative impact, e.g. smoking can cause cancer, whereas gain frame relates to feedback which indicates a positive impact of healthy behaviour, e.g. quitting smoking makes sleep quality better.

\subsection{Deviation and Countermeasures}

Deviation refers to the difference between the desired behaviour of a person and their actual behaviour [29]. Deviation consists of different types, and various facilitators can trigger it. Reducing or preventing deviation is achieved by employing a series of countermeasures, as summarised in Table 5. Due to space limitation and given that most of these deviation facilitators and countermeasures are self-explanatory; we will only elaborate on main and more complex elements from each category.

Table 5. Deviation from Behavioural Goals: Types, Facilitators and Countermeasures

\begin{tabular}{|l|l|}
\hline Type & Time-related; Frequency-related; Communication-related \\
tors & Goals that combined, conflict or compete with other goals; Source of the behavioural \\
goal; Social influence or peer pressure on the subject pursuing the goals; Setting \\
ambiguous goals with limited skills or time to attain the goals; Lack of commitment to the \\
set goals; Lack of proper timing of the goals; Setting complex goals that do not match \\
subjects' ability to attain them; Lack of self-efficacy to achieve the goal; Environmental \\
influence; Lack of a structured method for goal setting; Inaccessibility to resources to aid \\
goal attainment; Not understanding users' needs for the goals; Over-estimating \\
participants' self-efficacy level to achieve goals; Lack of understanding of barrier to gain \\
attainment; Timing of the behavioural goals; Frequency of executing the set goals. \\
$\begin{array}{l}\text { Detect and resolve goal conflict; Discuss barriers to goal attainment and ensure subjects } \\
\text { could adequately handle them; State clear goal outcome; Assess subjects commitment and } \\
\text { self-efficacy levels; Assess complexity of goal and analyse complex goals into series of } \\
\text { sub-goals; Review goals, re-strategise and analyse complex goals into series of sub-goals; } \\
\text { Monitor goal-related activities; Provide summary feedback in relation to goal } \\
\text { performance; Reminders; Perform manipulation checks to assess whether subjects } \\
\text { understand the goal or task; A proper explanation of the goal-related task; Task } \\
\text { familiarisation by asking subjects to try out a task similar to the goal; Persuade subjects to } \\
\text { verbally commit to the goal; Set unambiguous goals, Rewards. }\end{array}$
\end{tabular}

Deviation facilitators. These capture the various factors that can facilitate deviation.

- The timing of the goal refers to when goals are improperly time which could lead to conflicting, combined or competing goals. For instance, a smoking cessation goal may conflict with other goals, such as a weight loss goal or stress coping goal [30]. Similarly, individuals who have a heavy workload in conjunction with their 
goals could easily deviate due to their busy lifestyle [5]. It is, hence, vital to set goals so that their timing does not coincide with other personal activities.

- The frequency of executing the goal is essential for ensuring that the execution of goal-related actions does not overwhelm the subjects. If the rate of goal execution is not ideal for the subjects, they may lose interest in pursuing their goal.

- Inaccessibility to resources needed to achieve a goal, even temporarily, may affect the attainment of the goal. Examples of such resources include devices such as mobile phones and personal computers, or software application. To illustrate this point, a study by Gasser et al. [31], showed the difference in application usage between mobile phone application users and web application users which may be based on the lack of internet access and the restriction of mobile phone usage in the workplace, both been resources needed to accomplish the given goal.

- A complex task perception depends on the subject's self-efficacy, i.e. their perception of their ability to come up with the right strategies to achieve the task [1]. When the goals are set collaboratively, the experts could help subjects overcome the challenges that come as a barrier to attain the goal. They can also help them develop the required skills needed to continue pursuing their goals.

- Not understanding users' needs when setting a goal is a primary deviation facilitator and can be avoided by supporting users to comprehend their current behavioural patterns firstly. The ideation technique used in [32] could be adopted in the initial stages of the goal-setting process, to help understand the users and their needs.

- Source of behavioural goals whether goals are group-set, guided or participatory set, deviation could be attributed in part to insufficient communication between the subjects and experts involved in the process. As a result, the experts may not understand the subjects and their needs, and subsequently, may set goals that cannot be attainable. Also, when goals are assigned, the subjects' lack of participation in the process could affect their interest, commitment or motivation towards the goals, and this could lead to goal deviation or complete goal abandonment.

- Social influence and peer pressure occur when a person's feelings, emotional state and behaviour are affected by others' actions or behaviours [33]. When the behavioural change goals are set collaboratively, social influence could either have a positive effect, for instance, group members motivating each other toward goal attainment or a negative effect where people deviate from their goals, particularly those with low self-esteem. In a social setting, the individuals' actions are driven by the group norms which are most often than not agreed upon by the group members. When goal setting is performed collaboratively, it is essential that the group's, commitment and motivation are at the same or similar level to avoid social loafing and social compensation.

Deviation countermeasures. The applicability of the countermeasures largely depends on the deviation type and their facilitator. Some of the identified countermeasures are discussed here.

- Review goal, re-strategise and analyse complex goals into a series of sub-goals. When goal performance is lower than expected; then the goal could be reviewed to develop better attainment strategies. Poor performance could be the result of task complexity, low skills and ability levels, and not tackling other barriers to goal at- 
tainment. A complex task could be broken down into a series of subtasks that could relate to individuals' self-efficacy level which could help improve goal progress. Performance could be enhanced by adopting techniques such as barrier counselling, skill development approaches [34], and persuasion by providing subjects information concerning the approaches to use to attain their goals.

- Monitor goal-related activities. This technique involves monitoring and tracking the difference between the desired and actual behaviour which could be facilitated by an action-oriented approach, where subjects document their actions in pursuit of the goal. This process would enable the subjects to review their actions and identify the source of the deviation which may be related to some contextual or emotional factors and find the best plan for countering the deviation. Action planning is considered necessary during the early stages of behavioural change, while coping planning is assumed to be useful in the advanced stages of behaviour change, i.e. the action or maintenance stage [35].

- Obtain verbal commitment to goals. Verbal expression of commitment, and also the confidence to attain the behavioural goals may be obtained through persuasion. When subjects commit verbally to the setting of goals, this could help prevent deviation, especially when goals are set collaboratively. Subjects tend to adhere to the group goal once a verbal commitment is obtained due to fear of being socially excluded which may lead to loss of group identity, negative judgement, and blame for the group's failure to attain their behavioural change goals.

- Detect and resolve goal conflict. Conflicting goals should be identified and managed so that the subjects can progress toward attaining their goal. The environment could influence conflicting goals, i.e. the social setting of subjects, and also the source of the goals, i.e. when goals are assigned or set collaboratively. Goals could be prioritised to help resolve the conflicts among them. Also, the expert involved could facilitate negotiation with the subjects by applying, for example, logic and emotion negotiation approaches and help subjects understand that such conflict if not resolve may lead to deviation and lack of goal attainment in the long term.

- Assess individual self-efficacy and commitment. A subject's self-efficacy levels may influence their goal performance. Therefore, it is important to evaluate selfefficacy before setting the goals, to ensure that the right goals are chosen, in terms of difficulty and complexity levels. When goals are set collaboratively, subjects could be asked to confirm their goal commitment level verbally. To ensure that some of the subjects' responses are not influenced by the answers given by others in the group, all responses regarding goal commitment levels could be anonymised. Hence, reassuring subjects that given a lower response compare to others in the group will not lead to any negative reinforcement.

- Conduct manipulation checks. These checks are conducted to detect whether the subjects are paying attention to the set goals and goal-related tasks. Conducting manipulation checks could help assess the eligibility and credibility of the users in pursuing and attaining the goals. Persuasive techniques, such as tunnelling and conditioning, could be employed to aid subjects through these checks to help persuade them and improve their behaviour and commitment towards the set goals. 
Providing positive reinforcement and guidance through the process may help improve the outcome of such checks.

- Task explanation and task familiarisation. Regarding task explanation, before executing the goal-related task, a session could be conducted to explain to the subjects the task that they are expected to perform, ensuring that they understand what is expected of them. This process could be regarded as the induction phase of the goal setting process. Establishing an understanding of the task at an early stage could help prevent goal deviation which results from a lack of understanding of the goal-related task. Also, for familiarisation purposes, subjects could be asked to perform a task that is similar to the goal task before executing their goal related task.

- Goal summary feedback. Providing summary feedback may help motivate subjects to continue pursuing their goals and help them make an informed decision regarding the goals. Getting the feedback timing right, presenting it using an appropriate language and messaging style could help prevent deviation from goal. In a group setting, making the performance feedback visible to everyone may demotivate some subjects, therefore, eliciting the subjects' preferences is vital. Summary feedback may be provided in the form of a progress bar or an avatar.

- Rewards. Rewarding subjects positively, e.g. for goal attainment or significant goal progress, may help prevent deviation from the goal. The rewards could be provided personally or collectively based on the source of the goal and the subjects' preferences. When the rewards are to be displayed collectively, the individual differences within the group, i.e. personality, motivation, skills and confidence levels, should be carefully considered to ensure that reactance towards the rewards would not negatively affect their future goal performances.

\section{Conclusion and Future Work}

Our literature reviewed around goal setting led to the development of five reference checklists. We presented the reference checklists and elaborated on the various analysis and design considerations for persuasive systems and explained some of the conventional countermeasures for dealing with the deviation from goals. The five checklists are meant to provide a much easier reference point for researchers and practitioners using the strategy across different disciplines and build foundations for engineering goals embedded in persuasive information systems. Our future work will build on these initial results and further investigate the reference checklists in relation to behavioural change goals with the aim of providing a specification method for these goals. We will explore the set of stakeholders and their roles in the goal-setting process and also elicitation methods for behavioural goals and their socio-technical processes, e.g. in the reporting and adapting to behavioural change and progress.

Acknowledgement. This work has been partially supported by the EROGamb project funded jointly by GambleAware and Bournemouth University.

\section{References}

1. Locke, E.A., Latham, G.P.: Building a practically useful theory of goal setting and task motivation: A 35-year odyssey. American Psychologist 57(9), 705-717 (2002). 
2. Bandura, A., Simon, K.M.: The role of proximal intentions in self-regulation of refractory behavior. Cognitive Therapy and Research 1(3), 177-193 (1977).

3. Landers, R.N., Bauer, K.N., Callan, R.C.: Gamification of task performance with leaderboards: A goal setting experiment. Computers in Human Behavior 71, 508-515 (2015).

4. Consolvo, S., Klasnja, P.V., McDonald, D.W., Landay, J.A.: Goal-setting considerations for persuasive technologies that encourage physical activity. In: 4th international conference on Persuasive Technology, ACM, New York (2009).

5. Lin J.J., Mamykina, L., Lindtner S., Delajoux G., Strub H.B.: Fish'n'Steps: Encouraging Physical Activity with an Interactive Computer Game. In: Dourish P., Friday A. (eds.) 8th international conference on Ubiquitous Computing 2006, LNCS, vol. 4206, pp. 261-278. Springer, Verlag Berlin Heidelberg (2006).

6. Oinas-Kukkonen, H., Harjumaa, M.: Towards Deeper Understanding of Persuasion in Software and Information Systems. In: ACHI '08 Proceedings of the First International Conference on Advances in Human-Computer Interaction, pp. 200-205. IEEE, Washington, DC, USA (2008).

7. IJsselsteijn, W.A., De Kort, Y., Midden, C., Eggen, B., van de Hoven, E.: Persuasive Technology for Human Well-Being: Setting the Scene. In: IJsselsteijn W.A., de Kort Y.A.W., Midden C., Eggen B., van den Hoven E. (eds.) Persuasive 2006, LNCS, Vol. 3962, pp. 1-5. Springer, Berlin, Heidelberg (2006).

8. Fogg, B.J.: Persuasive Technology: Using Computers to Change What We Think and Do. Kaufmann Publishers, Inc. San Francisco, CA, USA (2003).

9. Cialdini, R.B.: Influence. (1984).

10. Klein, H.J., Wesson, M.J., Hollenbeck, J.R., Wright, P.M., DeShon, R.P.: The Assessment of Goal Commitment: A Measurement Model Meta-Analysis. Organisational behaviour and human decision processes 85(1), 32-55 (2009).

11. Steers, R.: Task-goal attributes, $\mathrm{n}$ achievement, and supervisory performance. Organizational. Behaviour and Human Performance 13(3), 392-403 (1975).

12. Oettingen, G., Pak, h., Schnetter., k.: Self-regulation of goal setting: turning free fantasies about the future into binding goals. Journal of Personality and Social Psychology 80(5), 736-753 (2001).

13. Fishbein, M.: A theory of reasoned action: some applications and implications. Nebr Symp Motiv 27, 65-116 (1980).

14. Ajzen, I.: The theory of planned behaviour. Organizational behaviour and human decision process 50, 179-211 (1991).

15. van Lamsweerde, A.: Goal-oriented requirements engineering: a guided tour. In: 5th IEEE International Symposium on Requirements Engineering, pp. 1-14. IEEE Computing Society, Toronto, Ontario, Canada, Canada (2001).

16. Jalali, S., Wohlin, C.: Systematic literature studies: database searches vs. backward snowballing. In: Proceedings of the ACM-IEEE international symposium on empirical software engineering and measurement, pp. 29-38. IEEE, Lund, Sweden (2013).

17. Farahat, T.: Applying the Technology Acceptance Model to Online Learning in the Egyptian Universities. Procedia Social and behavioral Sciences 64, 95-104 (2012).

18. Latham, G.P., Seijts, G.H.: The effects of proximal and distal goals on performance on a moderately complex task. Journal of Organizational Behavior 20 (4), 421-429 (1999).

19. Prochaska, J.O., DiClemente, C.C.: Stages and processes of self-change of smoking: Toward an integrative model of change. J Consult Clini Psychol 51 (3), 390-395 (1983).

20. Seijts, G.H., Latham, G.P.: The effect of distal learning, outcome, and proximal goals on a moderately complex task. Journal of Organizational Behavior 22(3), 291-307 (2001). 
21. Aunurrafiq, Sari, R.N., Basri, Y.M.: The Moderating Effect of Goal Setting on Performance Measurement System-managerial Performance Relationship. Procedia Economics and Finance 31, 876-884 (2015).

22. van Houwelingen, J.H., van Raaij, W.F.: The Effect of Goal-Setting and Daily Electronic Feedback on In-Home Energy Use. Journal of Consumer Research 16(1), 98-105 (1989).

23. Boekaerts, M., Corno, L.: Self-regulation in the classroom: A perspective on assessment and intervention. Applied Psychology 54(2), 199-231 (2005).

24. Locke, E.A., Latham, G.P.: New directions in goal-setting theory. Current Directions in Psychological Science 15(5), 265-268 (2006).

25. Erez, M., Arad, R.: Participative goal-setting: Social, motivational, and cognitive factors. Journal of Applied Psychology 71(4), 591-597 (1986).

26. Munson, S., Consolvo, S.: Exploring Goal-setting, Rewards, Self-monitoring, and Sharing to Motivate Physical Activity. In: 6th International conference on pervasive computing technologies for Healthcare, pp. 25-32. IEEE, San Diego, CA, USA (2012).

27. Alrobai, A., McAlaney, J., Dogan, H., Phalp, K., Ali, R.: Exploring the Requirements and Design of Persuasive Intervention Technology to Combat Digital Addiction. In: Bogdan C. et al. (eds.) Human-Centered and Error-Resilient Systems Development 2016, LNCS, vol. 9856, Springer, Heidelberg.

28. Locke, E.A., Latham, G.P., Erez, M.: The Determinants of Goal Commitment. The Academy of Management Review 13 (1), 23-39 (1988).

29. Reese, J.D., Leveson, N.G.: Software deviation analysis. In: ICSE'97 proceedings of the 19th international conference on Software engineering, pp. 250-260. ACM, New York, Boston, Massachusetts (1997).

30. Bodenheimer, T., Handley, M.A.: Goal-setting for behavior change in primary care: An exploration and status report. Patient Educ. Coun 76(2), 174-180 (2009).

31. Gasser, R., Brodbeck, D., Degen, M., Luthiger, J., Wyss, R., Reichlin, S.: Persuasiveness of a Mobile Lifestyle Coaching Application Using Social Facilitation. In: IJsselsteijn W.A., de Kort Y.A.W., Midden C., Eggen B., van den Hoven E. (eds.) Persuasive technology for human well-being 2006, LNCS, vol. 3962, pp. 27-38. Springer, Berlin, Heidelberg (2006).

32. Morschheuser, B., Hassan, L., Werder, K., Hamari, J.: How to design gamification? A method for engineering gamified software. Information and Software Technology 95, 219237 (2018).

33. Bandura, A.: Social foundations of thought and action: A social cognitive theory. PrenticeHall series in social learning theory. (1986).

34. Strecher, V.J., Seijts, G.H., Kok, G.J., Latham, G.P., Glasgow, R., DeVellis, B., Meertens, R.M., Bulger, D.W.: Goal Setting as a Strategy for Health Behavior Change. Health Education \& Behavior 22(2), 190-200 (1995).

35. Sniehotta, F.F., Scholz, U., Schwarzer, R.: Bridging the intention-behaviour gap: Planning, self-efficacy, and action control in the adoption and maintenance of physical exercise. Psychology \& Health 20 (2), 143-160 (2005). 


\section{Appendix 1. References for Reference Checklists}

\begin{tabular}{|c|c|}
\hline Reference checklists & Papers which where included in the literature review \\
\hline Sources of Behavioural Goals & $\begin{array}{l}\text { Bickmore et al (2005), Herrmanny et al (2016), Kim and Hamner } \\
\text { (1976), Landers et al (2015), Mangos and Steele-Johnson (2001), } \\
\text { Oettingen et al (2000), Schunk (1996), Smith et al (1990), Sobell et al } \\
\text { (1992), Van Hoye et al (2012). }\end{array}$ \\
\hline Behavioural Goal Identifiers & $\begin{array}{l}\text { Bandura and Simon (1977), Curtin et al (2001), Damon (1989), Emir } \\
\text { and Judge (2001), Fanta et al (2005), Mahfud et al (2011), Michelle et } \\
\text { al (2016), Miriam et al (1990), Nahrgang et al (2013), Nothwehr and } \\
\text { Yang (2007), Schweitzer et al (2004). }\end{array}$ \\
\hline $\begin{array}{l}\text { Behavioural Goal Elicitation } \\
\text { Methods }\end{array}$ & $\begin{array}{l}\text { Boekaerts and Corno (2005), Butler (1997), Consolvo et al (2006), } \\
\text { DeWalt et al (2009), Enggasser et al (2015), Erez and Arad (1986), } \\
\text { Litchfield et al (2011), Ussher et al (2003), Zhu et al (2012). }\end{array}$ \\
\hline $\begin{array}{l}\text { Behavioural Goals Monitoring } \\
\text { and Feedback }\end{array}$ & $\begin{array}{l}\text { Abrahamse (2007), Alitto et al (2016), Hamner and Harnett (1974), } \\
\text { Johnson et al (1997), Koskosas and Asimopoulos (2011), Lin et al } \\
\text { (2006), Loock et al (2013), Munson and Consolvo (2012), Ries et al } \\
\text { (2014), Schunk (1983), Schunk and Swartz (1993), Seijts and Latham } \\
\text { (2001), Vance and Colella (1990), Wijsman et al (2013), Zimmerman } \\
\text { et al (1992). }\end{array}$ \\
\hline $\begin{array}{l}\text { Deviation from Behavioural } \\
\text { Goals and Countermeasures }\end{array}$ & $\begin{array}{l}\text { Annesi (2002), Asmus et al (2015), Aunurrafiq et al (2015), Bergen et } \\
\text { al (1992), Bodenheimer and Handley (2009), Brusso and Orvis (2013), } \\
\text { Burke and Settles (2011), Consolvo et al (2009), Croteau (2004), Erez } \\
\text { and Zidon (1984), Gasser et al (2006), Glasgow et al (1996), Hansen } \\
\text { and Wills (2014), Koskosas (2009), Latham and Seijts (1999), } \\
\text { McCalley and Midden (2002), Oettingen et al (2001), Saini and La- } \\
\text { croix (2009), Shilts et al (2004), van Houwelingen and van Raaij } \\
\text { (1989). }\end{array}$ \\
\hline
\end{tabular}




\section{Appendix 2: References for Reference Checklists in Alphabetical Order}

Abrahamse, W., Steg, L., Vlek, C., Rothengatter, T.: The effect of tailored information, goal setting, and tailored feedback on household energy use, energy-related behaviours, and behavioural antecedents. Journal of Environmental Psychology 27(4), 265-276 (2007).

Alitto, J., Malecki, C., Coyle, S., Santuzzi, A.: Examining the effects of adult and peer mediated goal setting and feedback interventions for writing: Two studies. J of School Psychology 56, 89-109 (2016).

Annesi, J.J.: Goal-setting protocol in adherence to exercise by Italian adults. Perceptual Motor Skills 94(2), 453-8 (2002).

Asmus, S., Karl, F., Mohnen, A., Reinhart, G.: The impact of goal-setting on worker performance empirical evidence from a real-effort production experiment. Procedia CIRP 26, 127-132 (2015).

Aunurrafiq, Sari, R.N., Basri, Y.M.: The Moderating Effect of Goal Setting on Performance Measurement System-managerial Performance Relationship. Procedia Economics and Finance 31, 876-884 (2015).

Bandura, A., Simon, K.M.: The role of proximal intentions in self-regulation of refractory behavior. Cognitive Therapy and Research 1(3), 177-193 (1977).

Bergen, C.W.V., Barlow, S, Rosenthal, G.T.: The moderating effects of self-esteem and goal difficulty level on performance. College student journal 30(2), 262-268, (1992).

Bickmore, T., Caruso, L., Clough-Gorr, K.: Acceptance and Usability of a Relational Agent Interface by Urban Older Adults. In: CHI EA, pp.1212-1215. ACM, New York, NY (2005).

Bodenheimer, T., Handley, M.A.: Goal-setting for behavior change in primary care: An exploration and status report. Patient Educ. Coun 76(2), 174-180 (2009).

Boekaerts, M., Corno, L.: Self-regulation in the classroom: A perspective on assessment and intervention. Applied Psychology 54(2), 199-231 (2005).

Brusso, R.C., Orvis, K.A.: The impeding roles of initial unrealistic goal-setting on videogame-based training performance: identifying underpinning processes and a solution. Computer in Human behaviour 29(4), 1686-1694 (2013).

Burke, M., Settles, B.: Plugged into the Community: Social Motivators in Online Goal-Setting Groups. In: C\&T, pp. 1-10. ACM, Brisbane, (2011).

Butler, D. L.: The role of goal setting and self-monitoring in students self-regulated engagement in tasks. Paper presented at the annual meeting of the American Education Research Association, Chicago. ERIC Document Reprinting Services No. ED 409323 (1997).

Consolvo, S., Everitt, K., Smith, I. E., Landay, J. A.: April. Design requirements for technologies that encourage physical activity. In: Proceedings of the SIGCHI Conference on Human Factors in Computing Systems, pp. 457-466. ACM, New York, Montréal, Québec, Canada, (2006).

Consolvo, S., Klasnja, P.V., McDonald, D.W., Landay, J.A.: Goal-setting considerations for persuasive technologies that encourage physical activity. In: 4th international conference on Persuasive Technology, ACM, New York (2009).

Croteau, K.: A preliminary study on the impact of a pedometer-based intervention on daily steps, American Journal of Health Promotion 18, 217-220 (2004).

Curtin, L. Stephen, R. S., Bonenberger, J.L.: Goal setting and feedback in the reduction of heavy drinking in female college students. Journal of college student psychotherapy 15(3), 17-37 (2001).

Damon. B.: The Impact of goal specificity and task complexity on basketball skill development. Human Kinetics Journals 3(1), 34-47 (1989).

DeWalt, D.A., Davis, T.C., Wallace, A.S. Seligman, H.K., Bryant-Shilliday, B., Arnold, C. L., Freburger, J., Schillinger, D.: Goal setting in diabetes self-management: Taking the baby steps to success. Patient Education and Counselling 77(2), 218-223 (2009).

Emir, E., Judge, T.A.: Relationship of Core Self-Evaluations to Goal Setting, Motivation, and Performance. J. of App. Psychology 86(6), 1270-1279 (2001).

Enggasser, J.L., Hermos, J.A., Rubin, A., Lachowicz, M., Rybin, D., Brief, D. J., Roy, M., Helmuth, E., Rosenbloom, D., Keane, T.M.: Drinking goal choice and outcomes in a Web-based alcohol intervention: Results from Vet Change. Addictive Behaviours 42, 63-68 (2015).

Erez, M., Arad, R.: Participative goal-setting: Social, motivational, and cognitive factors. Journal of Applied Psychology 71(4), 591-597 (1986).

Erez, M., Zidon, I.: Effects of goal acceptance on the relationship of goal difficulty to performance. Journal of Applied Psychology 58, 69-78 (1984)

Fanta, E., Evansb, K.R., Zoub, S.: The moderating effect of goal-setting characteristics on the sales control systems-job performance relationship. Journal of business research. 58, 1214-1222 (2005).

Gasser, R., Brodbeck, D., Degen, M., Luthiger, J., Wyss, R., Reichlin, S.: Persuasiveness of a Mobile 
Lifestyle Coaching Application Using Social Facilitation. In: IJsselsteijn W.A., de Kort Y.A.W., Midden C., Eggen B., van den Hoven E. (eds.) Persuasive technology for human well-being 2006, LNCS, vol. 3962, pp. 27-38. Springer, Berlin, Heidelberg (2006).

Glasgow, R.E., Toobert, D.J., Hampson, S.E.: Effects of a Brief Office-Based Intervention to Facilitate Diabetes Dietary Self- Management. Diabetes Care 19(8), 835-842 (1996).

Hamner, W., Harnett, D.: Goal setting, performance and satisfaction in an interdependent task. Organizational Behaviour and Human Performance 12(2), 217-230 (1974).

Hansen, B., Wills, H.: The effects of goal setting, contingent reward, and instruction on writing skills. Journal of Applied Behaviour Analysis 47(1), 171-175 (2014).

Herrmanny, K., Ziegler, J., Dogangün, A.: Supporting Users in Setting Effective Goals in Activity Tracking, in Using Activity Theory to Model Context Awareness. Social Informatics 9638 (2), 15-26 (2016).

Johnson, L., Graham, S., Harris, K.R.: The Effects of Goal Setting and Self-Instruction on Learning a Reading Comprehension Strategy: A Study of Students with Learning Disabilities. Journal of learning disability 30(1), 80-91 (1997).

Kim, J.S., Hamner, W.C.: Effect of performance feedback and goal setting on productivity and satisfaction in an organizational setting. Journal of Applied Psychology 61(1), 48-57 (1976).

Koskosas, I.V., Asimopoulos, N.: Information systems security goals. International Journal of Advanced Science and Technology 27, 15-26 (2011).

Koskosas, I. V.: Communicating information systems goals - A case in internet banking security. ComSIS. 6(1), 71-92 (2009).

Landers, R.N., Bauer, K.N., Callan, R.C.: Gamification of task performance with leaderboards: A goal setting experiment. Computers in Human Behavior 71, 508-515 (2015).

Latham, G.P., Seijts, G.H.: The effects of proximal and distal goals on performance on a moderately complex task. Journal of Organizational Behavior 20 (4), 421-429 (1999).

Lin J.J., Mamykina, L., Lindtner S., Delajoux G., Strub H.B.: Fish'n'Steps: Encouraging Physical Activity with an Interactive Computer Game. In: Dourish P., Friday A. (eds.) 8th international conference on Ubiquitous Computing 2006, LNCS, vol. 4206, pp. 261-278. Springer, Verlag Berlin Heidelberg (2006).

Litchfield, R.C., Fan, J., Brown, V. R.: Directing idea generation using brainstorming with specific novelty goals. Motivation and Emotion 35(2), 135-143 (2011).

Loock, C.M., Staake, T., Thiesse, F.: Motivating energy-efficient behaviour with green is an investigation of goal setting and the role of defaults. MIS Quarterly 37(4), 1313-1332 (2013).

Mahfud, S., Pike, R., Mangena, M., Li, J.: Goal-setting participation and goal commitment: Examining the mediate roles of procedural fairness and interpersonal trust in a UK financial services organisation. The British Accounting Review 43 (2), 135-146 (2011).

Mangos, P.M., Steele-Johnson, D.: The Role of Subjective Task Complexity in Goal Orientation, SelfEfficacy, and Performance Relations. Human performance 14(2), 1532-7043 (2001).

McCalley, L.T., Midden, C.J.H.: Energy conservation through product-integrated feedback: The roles of goal-setting and social orientation. Journal of Economic Psychology 23(5), 589-603 (2002).

Michelle, D., Collen, F., Jayne, F.: An example of how to supplement goal setting to promote behavior change for families using motivational interviewing. Health communication 31(10), 1276-1283 (2016).

Miriam, E., Daniel, G., Nira, A.: Effects of goal difficulty, self-set goals, and monetary rewards on dual task performance. Organizational behavior and human decision processes 47(2), 247-269 (1990).

Munson, S., Consolvo, S.: Exploring Goal-setting, Rewards, Self-monitoring, and Sharing to Motivate Physical Activity. In: 6th International conference on pervasive computing technologies for Healthcare, pp. 25-32. IEEE, San Diego, CA, USA (2012).

Nahrgang, J.D., DeRue, S., Hollenbeck, J.R., Spitzmuller, M., Jundt, D.K., Llgen, D.R.: Goal setting in teams: The impact of learning and performance goals on process and performance. Organisational Behaviour and Human Decision Processes 122(1), 12-21 (2013).

Nothwehr, F., Yang, J.: Goal setting frequency and the use of behavioural strategies related to diet and physical activity. Health Education Research 22(4), 532-532 (2007).

Oettingen, G., Honig, G., Gollwitzer, P.M.: Effective self-regulation of goal attainment. International Journal of Educational Research 33 (7-8), 705-732 (2000).

Oettingen, G., Pak, h., Schnetter, k.: Self-regulation of goal setting: turning free fantasies about the future into binding goals. Journal of Personality and Social Psychology 80(5), 736-753 (2001).

Ries, A. V., Blackman, L. T., Page, R. A., Gizlice, Z., Benedict, S., Barnes, K., Kelsey, K., CarterEdwards, L.: Goal setting for health behaviour change: evidence from an obesity intervention for rural low-income women. Rural and Remote Health 14(2), (2014).

Saini. P., Lacroix, J.: Self-setting of physical activity goals and effects on perceived difficulty, importance and competence. In: 4th International Conference on Persuasive Technology. ACM, New York, 
Claremont, California (2009)

Schunk, D. H.: Developing children's self-efficacy and skills: The roles of social comparative information and goal setting. Contemporary Educational Psychology 8, 76-86 (1983).

Schunk, D.H., Swartz, C.: Goals and progress feedback: effects of self-efficacy and writing achievement. Contemporary education psychology 18(3), 337-354 (1993).

Schunk, D.H.: Goals and self-evaluative influences during children's cognitive skill learning. Educational Research Journal 33, 359 - 382 (1996).

Schweitzer, M.E., Ordonez, L., Douma, B.: Goals setting as a motivator of unethical behaviour. The Academy of Management Journal 47(3), $422-453$ (2004).

Seijts, G.H., Latham, G.P.: The effect of distal learning outcome, and proximal goals on a moderately complex task. Journal of Organizational Behavior 22(3), 291-307 (2001).

Shilts, M, K., Horowitz, M.S., Townsend, M, S.: An innovative approach to goal setting for adolescents: guided goal setting. Journal Nutrition Education Behaviour 36 (3), 155-156 (2004).

Smith, K.G., Locke, E.A., Barry, D.: Goal Setting, Planning, and Organizational Performance: An experimental simulation. Organizational Behaviour and Human Decision Processes 46(1),118-134 (1990). Sobell, M., Sobell, L., Bogardis, J., Leo, G., Skinner, W.: Problem drinkers' perceptions of whether treatment goals should be self-selected or therapist-selected. Behaviour Therapy 23(1), 43-52 (1992).

Ussher, M., West, R., McEwen, A., Taylor, A., Steptoe. A.: Efficacy of exercise counselling as an aid for smoking cessation: a randomized controlled trial. Addiction 98(4), 523-32 (2003).

van Houwelingen, J.H., van Raaij, W.F.: The Effect of Goal-Setting and Daily Electronic Feedback on InHome Energy Use. Journal of Consumer Research 16(1), 98-9 (1989).

Vance, J.R., Colella, A.: Effects of two types of feedback on goal acceptance and personal goals. Journal of Applied Psychology 75(1), 68-76 (1990).

Van Hoye, K., Boen, F., Lefevre, J.: The Effects of Physical Activity Feedback on Behavior and Awareness in Employees: Study Protocol for a Randomized Controlled Trial. Journal of telemedicine and applications 1-9 (2012).

Wijsman, C.A., Westendorp, R.G., Verhagen, E.A., Catt, M., Slagboom, P.E., de Craen, A.J., Broekhuizen, K., van Mechelen, W., van Heemst, D., van der Ouderaa, F., Mooijaart, S.P.: Effects of a Web-Based Intervention on Physical Activity and Metabolism in Older Adults: Randomized Controlled Trail. J Med Internet Res 15(11), (2013).

Zhu, H., Kraut R., Kittur, A.: Organizing without formal organization: group identification, goal setting and social modelling in directing the online production. In: Proceedings of the conference on computer supported cooperative work, pp. 935 - 944. ACM, New York, Seattle, WA, USA, (2012).

Zimmerman, B.J., Bandura, A., Martinez-Pons, M.: Self-Motivation for Academic Attainment: The Role of Self-Efficacy Beliefs and Personal Goal Setting. American Educational Research Journal 29(3), 663676 (1992). 